\title{
III-Nitride-Based Quantum Dots and Their Optoelectronic Applications
}

\author{
G. E. Weng ${ }^{1,2}$, A. K. Ling ${ }^{1}$, X. Q. Lv², J. Y. Zhang ${ }^{1}$, B. P. Zhang ${ }^{1,2, *}$
}

(Recevied 14 September; accepted 20 September 2011; published online 13 October 2011).

\begin{abstract}
During the last two decades, III-nitride-based quantum dots (QDs) have attracted great attentions for optoelectronic applications due to their unique electronic properties. In this paper, we first present an overview on the techniques of fabrication for III-nitride-based QDs. Then various optoelectronic devices such as QD lasers, QD light-emitting diodes (LEDs), QD infrared photodetectors (QDIPs) and QD intermediate band (QDIB) solar cells (SCs) are discussed. Finally, we focus on the future research directions and how the challenges can be overcome.
\end{abstract}

Keywords: III-nitride-based quantum dots; Lasers; Light-emitting diods; Infrared photodetectors; Solar cells

Citation: G. E. Weng, A. K. Ling, X. Q. Lv, J. Y. Zhang and B. P. Zhang, "III-Nitride-Based Quantum Dots and their Optoelectronic Applications", Nano-Micro Lett. 3 (3), 200-207 (2011). http://dx.doi.org/ $10.3786 / \mathrm{nml} \cdot \mathrm{v} 3 \mathrm{i3} \cdot \mathrm{p} 200-207$

\section{Introduction}

Investigations of III-nitride-based semiconductors have been very extensive for applications not only on light sources with short wavelength, but also on highspeed/high-power electron devices, particularly over the last decade. III-nitride with wurtzite crystal structure is a direct energy bandgap semiconductor and it has many unique properties including wide bandgaps, strong excitonic effects, high-saturation velocity, and high absorption and radiation coefficients [1]. In particular, the bandgap energy of $\mathrm{Al}_{x} \mathrm{In}_{y} \mathrm{Ga}_{z} \mathrm{~N}$ varies from 0.7 to $6.2 \mathrm{eV}$, depending on its composition $[2,3]$. In other words, III-nitride optical devices can cover the wide spectral range from ultraviolet (UV) to near infrared. To date, most research on optoelectronic devices has focused on the development of quantum well (QW) structures. However, devices incorporating InGaN/GaN QWs in the active region suffer from an "efficiency droop" at high injection levels, which has been attributed to alloy immiscibility and clustering in the well [4], defect-related recombination [5], carrier leakage [6], exciton dissociation [7] and Auger recombination $[8,9]$. Additionally, the existence of quantumconfined Stark effect (QCSE) induced by the strong built-in piezoelectric field in the highly strained high In-content InGaN/GaN multi-QWs (MQWs) results in a reduction in the carrier recombination rate by increasing the spatial separation between the electron and hole wave functions involved in the radiative recombination process $[10,11]$.

In order to improve the performance of nitride lightemitting diodes (LEDs) and laser diodes (LDs), obtaining a lower driving current density is essential for future applications (especially for short wavelength LDs). Some efforts have been shifted to the next generation III-nitride-based quantum dot (QD) devices such as QD lasers [12], QD LEDs [13], QD infrared photodetectors [14], and QD solar cells (SCs) [15]. Three dimensional quantum confinement of quantum dots gives rise to complete localization of electrons and holes and a discrete energy spectrum with $\delta$-function-like density of states, which increase the overlap of electron and hole wave functions and improve the recombination

\footnotetext{
${ }^{1}$ Department of Physics, Laboratory of Micro-Nano Optoelectronics, Xiamen University, Xiamen 361005, People's Republic of China

${ }^{2}$ MEMS Research Center, Xiamen University, Xiamen 361005, People's Republic of China

*Corresponding author. E-mail: bzhang@xmu.edu.cn
} 
rate of carriers. These in turn lead to higher brightness, lower driving currents, better temperature stability, and higher defect and radiation tolerance. As we know, the formation of QD structures comes from the strain relaxation of InGaN layer so that the piezoelectric polarization effect will be weaker and the efficiency droop will be much smaller than the QW structures [16]. Furthermore, it is much easier to grow higher In composition QDs and even 100\% InN QD structures can be grown [17]. This suggests that InGaN QDs are promising candidates to achieve efficient optical recombination at longer wavelength. Thus, QD devices have become new focus in both scientific research and industrial investment for its wide applications in recent years.

\section{Growth of QDs}

To obtain the QDs in nitride semiconductors, up to now, both self-assembling growth and selective growth techniques are well developed. For self-assembled QDs, three growth methods have been demonstrated. One is the Stranski-Krastanow (S-K) growth mode that is twodimensional (2D) growth of a few monolayers (MLs), called wetting layer, followed by three-dimensional (3D) island formation. Using the S-K mode, GaN dots have been fabricated on an AlN layer by molecular-beam epitaxy (MBE) $[18,19]$. Alternatively, InGaN dots on a GaN layer were also reported with MBE [20] and with metalorganic chemical vapor deposition (MOCVD) [2123]. In the second method, "anti-surfactants" are introduced. The antisurfactant, silicon, is believed to inhibit the GaN film from wetting the AlGaN surface due to the change in surface free energy. By this method, a successful fabrication of nanoscale GaN QDs in AlGaN confined layers has been first realized with MOCVD [24] and later with gas-source MBE [25]. In addition, InGaN dots on an AlGaN layer have been reported using low-pressure MOCVD [26]. The third method for self-formation of InGaN QDs comes from the intrinsic nature of InGaN ternary alloys since the compositional modulation due to phase separation would be energetically favored in this system [13,27,28]. Nistor et al. demonstrated that a phase decomposition, in InGaN, may lead to the formation of a nanostructure of nearly pure InN QDs [29].

Besides the self-assembled QDs, other approaches such as selective area growth have also been proposed. InGaN QDs fabricated by self-assembling are difficult to control the position and size while the shape and size of each QD can be artificially designed and controlled using lithographic techniques. Wang et al. has reported the fabrication of InGaN QDs by using a focused ion beam etching technique and selective area MOCVD growth [30]. However, it suffers from inevitable processinduced damage for QDs fabricated in this way [31].

\section{III-Nitride-Based QD Devices}

Nitride QDs are being used in lasers, LEDs, infrared photodetectors, SCs, single photon sources (SPSs), intersubband light sources and other optoelectronic devices.

\section{QD Lasers}

The concept of the QDs was proposed as artificial atoms for semiconductor laser applications by Arakawa and Sakaki for the first time in 1982 [32]. According to two different types of effects [33]: quantum effects and non-quantum effect, QD are considered to play an important role for achieving lower threshold current, enhanced differential gain, no chirping and high spectral purity. The quantum effect here is the effect resulting from the three-dimensional quantum confinement of electrons while the non-quantum effect includes the volume effect and the carrier localization effect.

Exciton-related lasing mechanisms are believed to be effective for achieving low threshold III-nitride LDs [34]. Biexcitons (exciton molecule) have also been theoretically demonstrated to play a significant role in further improving the LD performance [35]. Moreover, it has been shown both theoretically [36,37] and experimentally [16] that the piezoelectric field and resulting QCSE are significantly lower in InGaN/GaN QDs than in InGaN/GaN MQWs.

In 1997 Tanaka et al. demonstrated the stimulated emission from GaN dots [38]. Two years later, lasing oscillation of InGaN dots was observed by optically pumped excitation with a threshold energy of $6.0 \mu \mathrm{J}$ and a linewidth below $0.1 \mathrm{~nm}$ above the threshold at room temperature (RT) [12]. Although growth and optical properties of InGaN QDs are intensively studied currently $[22,39,40]$, there has been only very few reports on lasing from InGaN-based QDs, especially under an electrical injection. Nevertheless, an electrically injected InGaN/GaN QD laser has been reported recently [41]. As shown in Fig. 1, the laser exhibits a threshold current density of $\mathrm{J}_{t h}=1.2 \mathrm{kA} / \mathrm{cm}^{2}$, which is lower than those reported for QW lasers. Its smaller blueshift of $5 \mathrm{~nm}$ with increase of injection current could be due to a lower polarization field in the QDs compared with InGaN/GaN MQWs.

\section{QD LEDs}

Although high brightness nitride-based MQW LEDs are already commercially available, efforts are still necessary to enhance the LED output intensity. Using QDs instead of MQW is considered to be an effective approach. It is clear that phase separation induced InNlike QDs in InGaN active layers [13] is responsible for 

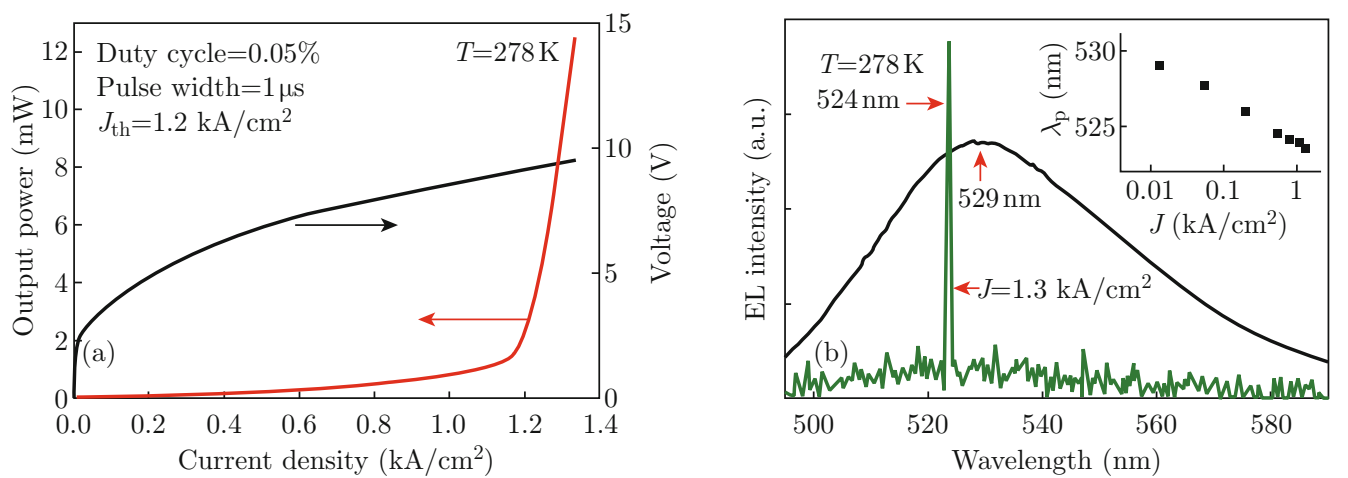

Fig. 1 (a) Light-current-voltage characteristics of $\operatorname{In}_{0.27} \mathrm{Ga}_{0.73} \mathrm{~N} / \mathrm{GaN}$ QD laser measured in the pulsed bias mode at $\mathrm{T}=$ $278 \mathrm{~K}$; (b) electroluminescence spectra of QD laser below (with dc bias) and above (with pulsed bias) threshold. Inset shows measured variation in spectral output peak wavelength with injection current (from Ref. [41]).

the hight brightness of LEDs. Blue-light emission has been reported from such QD structure fabricated by MBE [42]. Moreover, Damilano et al. [19] has demonstrated that intense RT visible luminescence can be obtained on $\mathrm{Si}(111)$ substrate and the emission energy can be continuously tuned from blue to orange by simply controlling the QD size. It has been shown that stacking of QD planes with properly chosen dot sizes gives rise to white light emission (see Fig. 2). As discussed in Section II, nitride QDs can be self-organized using growth interruption during the MOCVD growth $[22,23]$. By this method, L. W. Ji and Y. K. Su et al. $[43,44]$ have successfully fabricated blue LEDs with InGaN/GaN multiple quantum dot (MQD) structure, as is shown in Fig. 3(a). With a 20-mA DC injection current, the forward voltage was 3.1 and $3.5 \mathrm{~V}$ for MQD LED and conventional nitride-based MQW LED with the same structure, respectively. However, it was also found that EL peak position of the MQD LED is more sensitive to the amount of injection current, as compared to the conventional MQW LED, which disagrees with the theory prediction $[36,37]$ and the experimental result [16] that have been reported. They believe that the strain-induced QDs with deep localization of exitons (or carriers) can strengthen band-filling effect as the injection current increase. It has also been reported that the relative large size of QDs will lead to a stronger QCSE [17], because the smaller QDs have better overlap of electrons and holes wave functions. As the related mechanism is still not so clear in nitride QDs, more theoretical and experimental studies are needed.

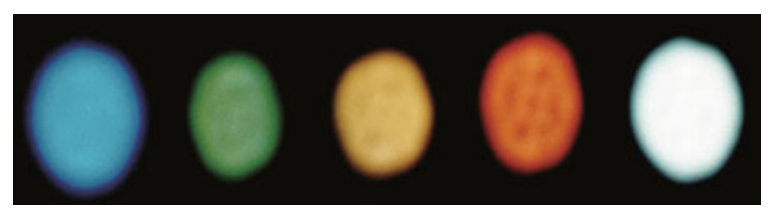

Fig. 2 Photographs of the light emitted at RT from GaN/AlN QDs on Si(111) excited by a $10 \mathrm{~mW}$ unfocused HeCd laser $\left(\sim 0.3 \mathrm{~W} / \mathrm{cm}^{2}\right)$ (from Ref. [19]).

High-brightness UV LEDs have great advantages in full-color displays and solid state lighting [45-47]. However, nitride-based UV LEDs suffer from a low efficiency and the small band offset between the InGaN well and the GaN barrier results in the weak thermal stability of electrical carriers in shallow InGaN QWs [46]. To improve the emission efficiency of an UV LED, an alternate active layer with QDs has been used due to its enhanced exciton binding energy and carrier localization effect [48]. Recently, UV LEDs with self-assembled InGaN QDs grown in a strain-induced S-K mode have been reported for the first time by I. K. Park et al. [49]. And in the same year, they demonstrated green LEDs with phase-separated In-rich InGaN QDs embedded in the InGaN active layer [50]. More recently, high efficiency green, yellow, and amber emission from InGaN/GaN dot-in-a-wire heterostructures has been observed [51]. Soon after that, InGaN/GaN LEDs with reduced efficiency droop have been demonstrated by $\mathrm{M}$. Zhang et al. [16] and P. Bhattacharya et al. [52] based on QDs.

\section{QD Infrared Photodetectors}

Due to their large conduction-band offset (about 1.75 $\mathrm{eV}$ for GaN/AlN [53]), semiconductor heterostructures based on III-nitrides are attracting new attention for intersubband (ISB) devices operating in the near-infrared spectral range and in particular in the $1.3 \sim 1.55 \mu \mathrm{m}$ wavelength window used for optical fiber communications. On the other hand, in the last few years, IIInitrides devices based on ISB transitions in QDs are potentially interesting especially for quantum-dot infrared photodetectors (QDIPs). The advantages of QDIPs, can mainly categorize in three parts [54]: (a) the 3D quantum confinement of the carriers, which results in the $\delta$-function-like density of states, and high sensitivity to the normal incident radiation without the use of a grating or corrugations as is often done in QWIPs [55-57], (b) reduced electron-phonon scattering, which elongates the carrier lifetime, and high current gain [5860], (c) high-temperature operations [61,62].

The fabrication and characterization of a GaN/AlN 

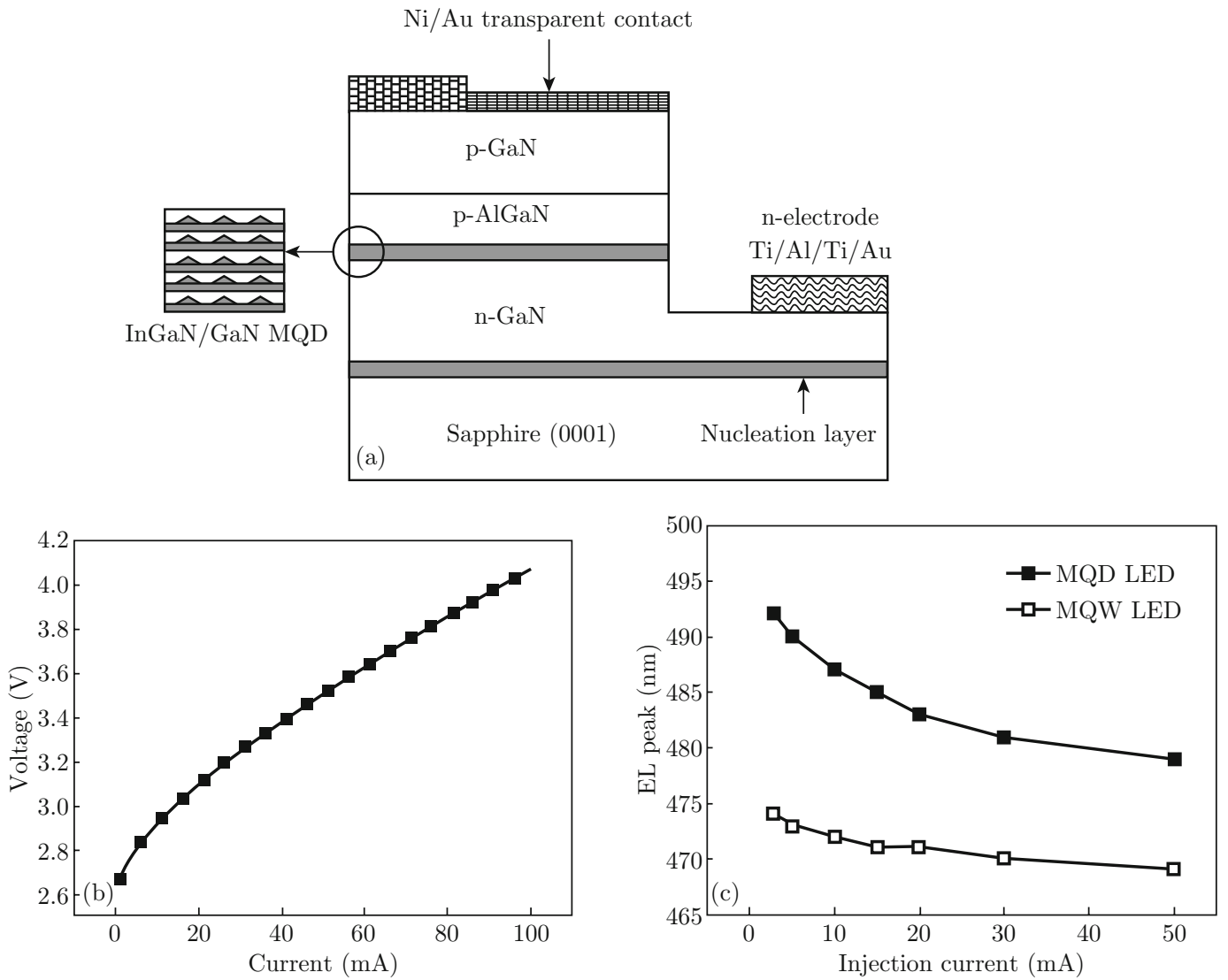

Fig. 3 (a) Schematic structure for the blue LED with InGaN/GaN MQDs; (b) I-V characteristics of the MQD LED. the forward voltage is $3.1 \mathrm{~V}$ at $20 \mathrm{~mA}$ injection current; (c) Dominated wavelength of EL spectra as a function of injection current for the MQD LED and conventional MQW LED (see Ref. [43,44] for details).

QDIP has been reported for the first time by Doyennette et al. [63]. The photocurrent spectrum is peaked at $\lambda=1.38 \mu \mathrm{m}$ at a temperature of $77 \mathrm{~K}$ and it is $\mathrm{p}$ polarized. Then GaN/AlN QD photodetectors have been successfully demonstrated at RT in the fiberoptics spectral range $[64,65]$. Moreover, strong absorption at telecommunication wavelengths in heavily $\mathrm{Si}$ doped GaN/AlN QD superlattices has been observed $[66,67]$. Recently, a novel long wavelength infrared QD photodetector has been presented [54]. The structure is shown in Fig. 4. The proposed device has demonstrated

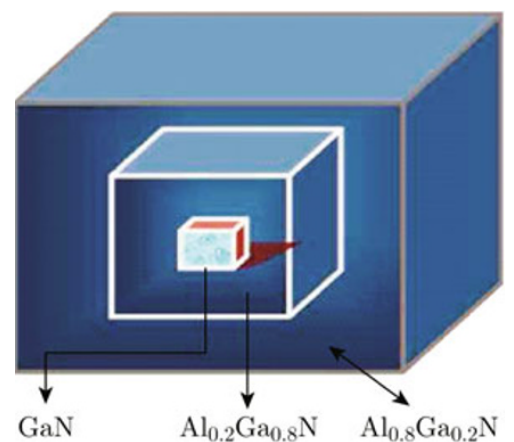

Fig. 4 The proposed cubic shaped GaN QD within a large $\mathrm{Al}_{0.2} \mathrm{Ga}_{0.8} \mathrm{~N}$ QD (from Ref. [54]). exceptionally low dark current, low noise, and high detectivity.

\section{QD Solar Cell}

Third-generation photovoltaics with an intermediateband (IB) has been proposed in order to increase the efficiency of SCs $[68,69]$. Theoretical models predict that the maximum solar energy conversion is up to $63.2 \%$ [70] for this type of SC, which represents a higher figure than the one predicted for a tandem two cell device $(55.4 \%)$ and a single cell device $(40.7 \%)$.

The III-nitride quantum dots intermediate band (QDIB) SCs have been theoretically studied in recent years. Cánovas et al. [15] have calculated the optimum nitrogen content in order to obtain the maximum ideal efficiency in selected III- $\mathrm{N}_{\mathrm{x}}-\mathrm{V}_{1-\mathrm{x}}$ highly mismatched alloys (HMAs) according to the ideal IB SC theory. Efficiency over $60 \%$ is predicted with a comparatively lower nitrogen content of $1 \% \sim 3.5 \%$ in the HMAs. In addition, the band gap of $\operatorname{In}_{\mathrm{x}} \mathrm{Ga}_{1-\mathrm{x}} \mathrm{N}$ varies from 0.77 to $3.44 \mathrm{eV}$ depending on $\mathrm{x}$, which corresponds very closely to the solar spectrum $(0.5 \sim 3.5 \mathrm{eV})$. It has been shown that $\operatorname{In}_{\mathrm{x}} \mathrm{Ga}_{1-\mathrm{x}} \mathrm{N}$ dots can be formed on GaN layer perfectly even when $\mathrm{x}=1$ [17], despite the large lattice mismatch $(11 \%)$ between GaN and InN. Thus, a multi- 
stacked structure of different-sized InGaN QDs in iregion of a p-i-n SC structure, called "rainbow" SC, has been proposed for maximum solar conversion efficiency [71-73]. As shown in Fig. 5(a), the $\operatorname{In}_{\mathrm{x}} \mathrm{Ga}_{1-\mathrm{x}} \mathrm{N}$ QD layers are placed in the i-region which is further sandwiched by GaN barrier layers. Each layer of the same sized QDs supports only one confined state of electron. Different-sized QDs in different layers of SC efficiently overlap with the large part of the sunlight spectra. The corresponding energy-band diagram is shown in Fig. 5(b). Theoretical study on $\operatorname{In}_{\mathrm{x}} \mathrm{Ga}_{1-\mathrm{x}} \mathrm{N} / \mathrm{GaN}$ QDIB SC by solving the Schrödinger-equation in light of the Kronig-Penney model has also been reported [74]. However, there is no report on nitride-based QDIB SC in experiment.

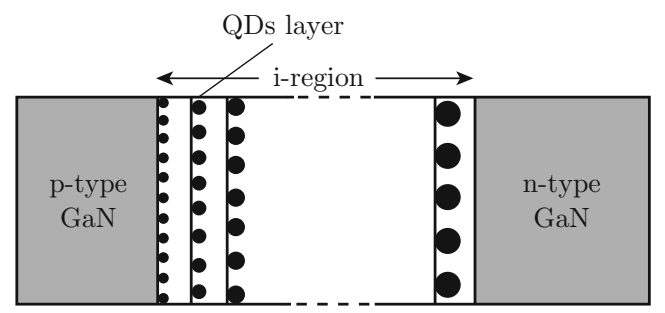

(a)

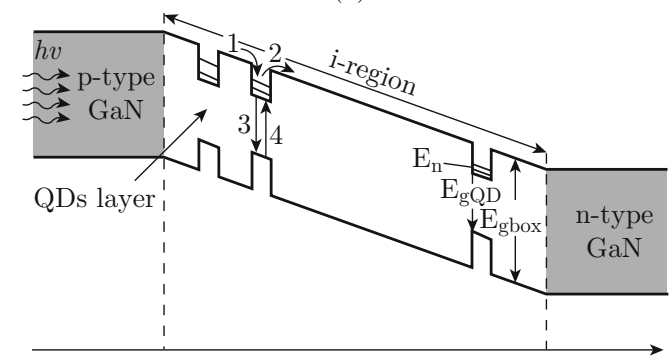

(b)

Fig. 5 (a) The p-i-n QD SC structure with different sized QDs in each layer; (b) Energy-band diagram of p-i-n QD SC and generation-recombination processes in QDs for one type of carriers. Depletion layers in $\mathrm{p}$ and $\mathrm{n}$ layers are neglected (from Ref. [71]).

More optoelectronics applications of III-nitride-based QDs have been proposed in these years such as SPSs [75-77] and intersubband light sources [78]. A triggered single-photon emission, which is a key requirement for the development of quantum key distribution systems [79] and for quantum computing schemes based on linear optics [80], from GaN QDs at temperature up to $200 \mathrm{~K}$ has been reported recently [75]. It is a promising step towards realizing practical higher-operationtemperature single photon sources in the short wavelength region.

\section{Challenges and Perspectives}

Currently InGaN-based LDs are suffering from a high threshold current density, a few orders of magnitude higher than that for GaAs-based LDs [81-83].
It is essential to continuously improve the performance of InGaN-based LDs. For ISB light-emitting devices, one major difficulty is the expected weak luminescence efficiency resulting from the ultra-short electron-LO phonon scattering times $(0.15 \sim 0.4 \mathrm{ps})$ in these highlyionic semiconductors [84].

For further progress in the development of III-nitride materials and devices, many challenges still remain. These include difficulties in the growth of InGaN across the full alloy range [85], the high dislocation density of typically $10^{10} / \mathrm{cm}^{2}$ [86], the lack of suitable substrates [87] and the huge built-in electric field of several $\mathrm{MV} / \mathrm{cm}$ originating from both spontaneous and piezoelectric polarizations [88]. As a consequence, a giant QCSE takes place, which induces a large dipole due to electron and hole spatial separation. Consequently, the efficiency of nitride-based optoelectronic devices is presently affected by these limitations. Moreover, for nitride QDs, there are several extra problems that should be resolved [89]. Firstly, it is still difficult to fabricate a uniform QD structure with high density. Secondly, the understanding of the growth mechanism of InGaN QDs by the extensively used metal-organic chemical vapor deposition MOCVD is very limited. Finally, for growth of electrical injection LDs, the high growth temperature for the layers such as p-type layers (or even GaN barrier for InGaN QDs) that have to be deposited after InGaN QDs is another important issue. And one of the obstacles in the completion of devices is the difficulty of accessing the dots electrically.

Nevertheless, due to the rapid progress in QD growth technology and the continuing challenges in development of III-nitride materials, both theoretically and experimentally, the physical and optical properties of IIInitride QDs will be understood better. Consequently, novel applications are believed to emerge. Apart from the optoelectronic devices discussed here, III-nitride QDs will certainly be used for other optoelectronic devices such as optical amplifiers and vertical cavity surface emitting lasers (VCSELs) in the near future.

\section{Summary}

We have reviewed the recent progress of III-nitridebased QDs and their optoelectronic applications such as lasers, LEDs, infrared photodetectors, and SCs. As discussed in Section II, both self-assembling growth and selective growth techniques are well developed to obtain QDs of nitride semiconductors. Recently, an electrically injected InGaN/GaN QD green $(\lambda=524$ $\mathrm{nm})$ laser has been reported for the first time. Additionally, many efforts have been made to obtain highperformance LEDs by adopting dot structures. Thanks to the large conduction-band offset for GaN/AlN, the QDIPs based on ISB transitions have been successfully demonstrated at RT in the fiber-optics spectral range. 
Moreover, the III-nitrides QDIB SCs or "rainbow" SCs are expected to increase the solar energy conversion efficiency over $63 \%$. Finally, we point out the possible difficulties and perspectives associated with growth and applications of III-nitride QDs.

\section{References}

[1] S. C. Jain, M. WIllander, J. Narayan and R. V. Overstraeten, J. Appl. Phys. 87, 965 (2000). http://dx. doi.org/10.1063/1.371971

[2] T. Matsuoka, H. Okamoto, M. Nakao, H. Harima and E. Kurimoto, Appl. Phys. Lett. 81, 1246 (2002). http://dx.doi.org/10.1063/1.1499753

[3] I. Vurgaftman and J. R. Meyer, J. Appl. Phys. 94, 3675 (2003). http://dx.doi.org/10.1063/1.1600519

[4] P. Ruterana, S. Kret, A. Vivet, G. Maciejewski and P. Dluzewski, J. Appl. Phys. 91, 8979 (2002). http:// dx.doi.org/10.1063/1.1473666

[5] T. Mukai, M. Yamada and S. Nakamura, Jpn. J. Appl. Phys. 38, 3976 (1999). http://dx.doi.org/10.1143/ JJAP. 38. 3976

[6] M. H. Kim, M. F. Schubert, Q. Dai, J. K. Kim, E. F. Schubert, J. Piprek and Y. Park, Appl. Phys. Lett. 91, 183507 (2007). http://dx.doi.org/10.1063/1. 2800290

[7] S. F. Chichibu, T. Sota, K. Wada and S. Nakamura, J. Vac. Sci. Technol. B 16, 2204 (1998). http://dx.doi. org/10.1116/1.590149

[8] Y. C. Shen, G. O. Müller, S. Watanabe, N. F. Gardner, A. Munkholm and M. R. Krames, Appl. Phys. Lett. 91, 141101 (2007). http://dx.doi.org/10.1063/1. 2785135

[9] M. Zhang, P. Bhattacharya, J. Singh and J. Hinckley, Appl. Phys. Lett. 95, 201108 (2009). http://dx.doi. org/10.1063/1.3266520

[10] P. Waltereit, O. Brandt, A. Trampert, H. T. Grahn, J. Menniger, M. Ramsteiner, M. Reiche and K. H. Ploog, Nature 406, 865(2000). http://dx.doi.org/10.1038/ 35022529

[11] N. A. Shapiro, H. Feick, W. Hong, M. Cich, R. Armitage and E. R. Weber, J. Appl. Phys. 94, 4520 (2003). http://dx.doi.org/10.1063/1.1607521

[12] K. Tachibana, T. Someya, Y. Arakawa, R. Werner and A. Forchel, Appl. Phys. Lett. 75, 2605 (1999). http:// dx.doi.org/10.1063/1.125092

[13] Y. Narukawa, Y. Kawami, M. Funato, Shizuo Fujita and Shigeo Fujita, Appl. Phys. Lett. 70, 981 (1997). http://dx.doi.org/10.1063/1.118455

[14] E. Monroy, F. Guillot, S. Leconte, L. Nevou, L. Doyennette, M. Tchernycheva, F. H. Julien, E. Baumann, F. R. Giorgetta and D. Hofstetter, J. Mater. Sci. : Mater. Electron. 19, 821 (2008). http://dx.doi.org/ 10.1007/s10854-007-9482-3

[15] E. Cánovas, A. Martí and W. Walukiewicz, Appl. Phys. Lett. 93, 174109 (2008). http://dx.doi.org/ 10.1063/1. 3013570
[16] M. Zhang, P. Bhattacharya and W. Guo, Appl. Phys. Lett. 97, 011103 (2010). http://dx.doi.org/ 10.1063/1.3460921

[17] T. D. Moustakas, T. Xu, C. Thomidis, A. Y. Nikiforov, L. Zhou and D. J. Smith, phys. stat. sol. A 205, 2560 (2008). http://dx.doi.org/10.1002/pssa. 200880222

[18] B. Daudin, F. Widmann, G. Feuillet, Y. Samson, M. Arlery and J. L. Rouvière, Phys. Rev. B 56, R7069 (1997). http://dx.doi.org/10.1103/ PhysRevB.56.R7069

[19] B. Damilano, N. Grandjean, F. Semond, J. Massies and M. Leroux, Appl. Phys. Lett. 75, 962 (1999). http://dx.doi.org/10.1063/1.124567

[20] C. Adelmann, J. Simon, N. Pelekanos, Y. Samson, G. Feuillet and B. Daudin, Phys. Stat. Sol. (a) 176,639 (1999). http://dx.doi.org/10. 1002/ (SICI) 1521-396X (199911) 176: 1\$<\$639: : AID-PSSA639\$>\$3. 0. CO; $2-Z$

[21] K. Tachibana, T. Someya and Y. Arakawa, Appl. Phys. Lett. 74, 383 (1999). http://dx.doi.org/10.1063/1. 123078

[22] L. W. Ji, Y. K. Su, S. J. Chang, L. W. Wu, T. H. Fang, J. F. Chen, T. Y. Tsai, Q. K. Xue and S. C. Chen, J. Cryst. Growth 249, 144 (2003). http://dx.doi.org/ 10.1016/S0022-0248(02)02130-9

[23] L. W. Ji, Y. K. Su, S. J. Chang, L. W. Wu, T. H. Fang, Q. K. Xue, W. C. Lai and Y. Z. Chiou, Mater. Lett. 57, 4218 (2003). http://dx.doi.org/10.1016/ S0167-577X (03) 00293-3

[24] S. Tanaka, S. Iwai and Y. Aoyagi, Appl. Phys. Lett. 69, 4096 (1996). http://dx.doi.org/10.1063/1.117830

[25] X. Q. Shen, S. Tanaka, S. Iwai and Y. Aoyagi, Appl. Phys. Lett. 72, 344 (1998). http://dx.doi.org/10. 1063/1.120731

[26] H. Hirayama, S. Tanaka, P. Ramvall and Y. Aoyagi, Appl. Phys. Lett. 72, 1736 (1998). http://dx.doi. org/10.1063/1.121168

[27] A. Koukitsu, N. Takahashi, T. Taki and H. Seki, Jpn. J. Appl. Phys. 35, L673 (1996). http://dx.doi.org/ 10. 1143/JJAP. 35. L673

[28] I-h. Ho and G. B. Stringfellow, Appl. Phys. Lett. 69, 2701 (1996). http://dx.doi.org/10.1063/1.117683

[29] L. Nistor, H. Bender, A. Vantomme, M. F. Wu, J. V. Landuyt, K. P. O'Donnell, R. Martin, K. Jacobs and I. Moerman, Appl. Phys. Lett. 77, 507 (2000). http:// dx.doi.org/10.1063/1.127026

[30] J. Wang, M. Nozak, M. Laehab, Y. Ishikawa, R. S. Qhalid Fareed, T. Wang, M. Hao and S. Sakai, Appl. Phys. Lett. 75, 950 (1999). http://dx.doi.org/10. 1063/1. 124564

[31] J. L. Merz, S. Lee and J. K. Furdyna, J. Cryst. Growth 184, 228 (1998). http://dx.doi.org/10. 1016/S0022-0248(98)80050-X

[32] Y. Arakawa and H. Sakaki, Appl. Phys. Lett. 40, 939 (1982). http://dx.doi.org/10.1063/1.92959

[33] Y. Arakawa, T. Someya and K. Tachibana, IEICE Trans. Electron. E83-C, 564 (2000).

[34] T. Uenoyama, Phys. Rev. B 51, 10228 (1995). http:// dx.doi.org/10.1103/PhysRevB.51.10228 
[35] W. Huang and F. Jain, J. Appl. Phys. 87, 7354 (2000). http://dx.doi.org/10.1063/1.372993

[36] S. Schulz and E. P. O'Reilly, Phys. Rev. B 82, 033411 (2010). http://dx.doi.org/10.1103/ PhysRevB. 82.033411

[37] Y. R. Wu, Y. Y. Lin, H. H. Huang and J. Singh, J. Appl. Phys. 105, 013117 (2009). http://dx.doi.org/ 10.1063/1.3065274

[38] S. Tanaka, H. Hirayama, Y. Aoyagi, Y. Narukawa, Y. Kawakami, Shizuo Fujita and Shigeo Fujita, Appl. Phys. Lett. 71, 1299 (1997). http://dx.doi.org/10. 1063/1. 119877

[39] J. S. Huang, Z. Chen, X. D. Luo, Z. Y. Xua and W. K. Ge, J. Cryst. Growth 260, 13 (2004). http://dx. doi.org/10.1016/j.jcrysgro. 2003.08.008

[40] R. A. Oliver, G. A. D. Briggs, M. J. Kappers, C. J. Humphreys, S. Yasin, J. H. Rice, J. D. Smith and R. A. Taylor, Appl. Phys. Lett. 83, 755 (2003). http:// dx.doi.org/10.1063/1.1595716

[41] M. Zhang, A. Banerjee, C. S. Lee, J. M. Hinckley and P. Bhattacharya, Appl. Phys. Lett. 98, 221104 (2011). http://dx.doi.org/10.1063/1.3596436

[42] F. Widmann, J. Simon, B. Daudin, G. Feuillet, J. L. Rouvie're, N. T. Pelekanos and G. Fishman, Phys. Rev. B 58, R15989 (1998). http://dx.doi.org/10. 1103/PhysRevB.58.R15989

[43] L. W. Ji, Y. K. Su, S. J. Chang, C. S. Chang, L. W. Wu, W. C. Lai, X. L. Du and H. Chen, J. Cryst. Growth 263, 114 (2004). http://dx.doi.org/ 10.1016/j.jcrysgro.2003.08.083

[44] Y. K. Su, S. J. Chang, L. W. Ji, C. S. Chang, L. W. Wu, W. C. Lai, T. H. Fang and K. T. Lam, Semicond. Sci. Technol. 19, 389 (2004). http://dx.doi.org/10. 1088/0268-1242/19/3/016

[45] S. Nakamura, S. Senoh, N. Iwasa and S. Nagahama, Jpn. J. Appl. Phys. 34, L797 (1995). http://dx.doi. org/10.1143/JJAP. 34.L797

[46] C. C. Pan, C. M. Lee, J. W. Liu, G. T. Chen and J. I. Chyi, Appl. Phys. Lett. 84, 5249 (2004). http://dx. doi.org/10.1063/1.1765207

[47] M. K. Kwon, I. K. Park, S. H. Baek, J. Y. Kim and S. J. Park, J. Appl. Phys. 97, 106109 (2005). http://dx. doi.org/10.1063/1.1904151

[48] C. Adelmann, J. Simon, G. Feuillet, N. T. Pelekanos, B. Daudin and G. Fishman, Appl. Phys. Lett. 76, 1570 (2000). http://dx.doi.org/10.1063/1.126098

[49] I. K. Park, M. K. Kwon, S. B. Seo, J. Y. Kim, J. H. Lim and S. J. Park, Appl. Phys. Lett. 90, 111116 (2007). http://dx.doi.org/10.1063/1.2712804

[50] I. K. Park, M. K. Kwon, J. O. Kim, S. B. Seo, J. Y. Kim, J. H. Lim, S. J. Park and Y. S. Kim, Appl. Phys. Lett. 91, 133105 (2007). http://dx.doi.org/ 10.1063/1.2790783

[51] Y. L. Chang, J. L. Wang, F. Li and Z. Mi, Appl. Phys. Lett. 96, 013106 (2010). http://dx.doi.org/ 10.1063/1.3284660

[52] P. Bhattacharya, M. Zhang and J. Hinckley, Appl. Phys. Lett. 97, 251107 (2010). http://dx.doi.org/ $10.1063 / 1.3527935$
[53] M. Tchernycheva, L. Nevou, L. Doyennette, F. H. Julien, E. Warde, F. Guillot, E. Monroy, E. BelletAmalric, T. Remmele and M. Albrecht, Phys. Rev. B 73, 125347 (2006). http://dx.doi.org/10.1103/ PhysRevB.73.125347

[54] A. Asgari and S. Razi, Opt. Exp. 18, 14604, (2010). http://dx.doi.org/10.1364/OE.18.014604

[55] D. Pan, E. Towe and S. Kennerly, Appl. Phys. Lett. 73, 1937 (1998). http://dx.doi.org/10.1063/1.122328

[56] A. Stiff, S. Krishna, P. Bhattacharya and S. Kennerly, Appl. Phys. Lett. 79, 421 (2001). http://dx.doi.org/ 10.1063/1.1385584

[57] L. Jiang, S. S. Li, N. Yeh, J. Chyi, C. E. Ross and K. S. Jones, Appl. Phys. Lett. 82, 1986 (2003). http:// dx.doi.org/10.1063/1.1540240

[58] S. Y. Wang, M. C. Lo, H. Y. Hsiao, H. S. Ling and C. P. Lee, Infra. Phys. Technol. 50, 166 (2007). http:// dx.doi.org/10.1016/j.infrared.2006.10.027

[59] U. Bockelmann and G. Bastard, Phys. Rev. B 42, 8947 (1990). http://dx.doi.org/10.1103/PhysRevB. 42.8947

[60] Z. Ye, J. C. Campbell, Z. Chen, E.-T. Kim and A. Madhukar, Appl. Phys. Lett. 83, 1234 (2003). http:// dx.doi.org/10.1063/1.1597987

[61] S. Chakrabarti, A. D. Stiff-Roberts, P. Bhattacharya, S. Gunapala, S. Bandara, S. B. Rafol and S. W. Kennerly, IEEE Photon. Technol. Lett. 16, 1361 (2004). http://dx.doi.org/10.1109/LPT. 2004.825974

[62] S. F. Tang, C. D. Chiang, P. K. Weng, Y. T. Gau, J. J. Luo, S. T. Yang, C. C. Shih, S. Y. Lin and S. C. Lee, IEEE Photon. Technol. Lett. 18, 986 (2006). http:// dx.doi.org/10.1109/LPT. 2006.873458

[63] L. Doyennette, L. Nevou, M. Tchernycheva, A. Lupu, F. Guillot, E. Monroy, R. Colombelli and F. H. Julien, Electron. Lett. 41, 1077 (2005). http://dx.doi.org/ 10. 1049/el:20052598

[64] A. Vardi, N. Akopian, G. Bahir, L. Doyennette, M. Tchernycheva, L. Nevou, F. H. Julien, F. Guillot and E. Monroy, Appl. Phys. Lett. 88, 143101 (2006). http://dx.doi.org/10.1063/1.2186108

[65] L. Doyennettea, A. Vardib, F. Guillotc, L. Nevoua, M. Tchernychevaa, A. Lupua, R. Colombellia, G. Bahirb, E. Monroyc and F. H. Juliena, Superlattices and Microstructures 40, 262 (2006). http://dx.doi.org/10. 1016/j.spmi. 2006.09.017

[66] M. Tchernycheva, L. Nevou, L. Doyennette, A. Helman, R. Colombelli, F. H. Julien, F. Guillot, E. Monroy, T. Shibata and M. Tanaka, Appl. Phys. Lett. 87, 101912 (2005). http://dx.doi.org/10.1063/1. 2042540

[67] F. Guillot, E. Bellet-Amalric, E. Monroy, M. Tchernycheva, L. Nevou, L. Doyennette, F. H. Julien, Le Si Dang, T. Remmele M. Albrecht, T. Shibata and M. Tanaka, J. Appl. Phys. 100, 044326 (2006). http:// dx.doi.org/10.1063/1.2335400

[68] A. Luque, A. Martí, P.Wahnon, L. Cuadra, C. Tablero, C. Stanley, A. McKee, D. Zhou, R. Konenkamp, R. Bayón, A. Belaidi, J. Alonso, J. Ruiz, J. Fernández, P. Palacios and N. López, in: Proceedings of the 29th 
IEEE PVSC, New Orleans, LA, 1190, (2002). http:// dx.doi.org/10.1109/PVSC. 2002.1190820

[69] G. Cassaboisa, C. Kammerera, C. Voisin, C. Delalande, P.Ph. Roussignol and J.M. Gérard, Physica E 13, 105 (2002). http://dx.doi.org/10.1016/ S1386-9477(01)00497-0

[70] A. Luque and A. Martí, Phys. Rev. Lett. 78, 5014 (1997). http://dx.doi.org/10.1103/PhysRevLett. 78.5014

[71] H. Movla, F. Sohrabi, J. Fathi, H. Babaei, A. Nikniazi, K. Khalili and N. Gorji, Turk. J. Phys. 34, 97 (2010). http://dx.doi.org/10.3906/fiz-1002-19

[72] N. Gorji, H. Movla, F. Sohrabi, A. Hosseinpour, M. Rezaei and H. Babaei, Physica E 42, 2353 (2010). http://dx.doi.org/10.1016/j.physe. 2010.05.014

[73] A. Rostami, K. Abbasian and N. Gorji, IJTPE Journal 3, 106 (2011).

[74] Q. Deng, X. Wang, C. Yang, H. Xiao, C. Wang, H. Yin, Q. Hou, J. Li, Z. Wang and X. Hou, Physica B 406, 73 (2011). http://dx.doi.org/10.1016/j. physb.2010.10.020

[75] S. Kako, C. Santori, K. Hoshino, S. Götzinger, Y. Yamamoto and Y. Arakawa, nature materials 5, 887 (2006). http://dx.doi.org/10.1038/nmat1763

[76] A. F. Jarjour, R. A. Oliver and R. A. Taylor, phys. stat. sol. A 206, 2510 (2009). http://dx.doi.org/10. 1002/pssa. 200824455

[77] H. Dartsch, C. Tessarek, T. Aschenbrenner, S. Figge, C. Kruse, M. Schowalter, A. Rosenauer and D. Hommel, J. Cryst. Growth 320, 28 (2011). http://dx. doi. org/10.1016/j.jcrysgro.2010.12.008

[78] L. Nevou, F. H. Julien,M. Tchernycheva, F. Guillot, E. Monroy and E. Sarigiannidou, Appl. Phys. Lett.
92, 161105 (2008). http://dx.doi.org/10.1063/1. 2913756

[79] B. Lounis and M. Orrit, Rep. Prog. Phys. 68, 1129 (2005). http://dx.doi.org/10.1088/0034-4885/68/ 5/R04

[80] E. Knill, R. Laflamme and G. J. Milburn, Nature 409, 46 (2001). http://dx.doi.org/10.1038/35051009

[81] S. J. Pearton, J. C. Zolper, R. J. Shul and F. Ren, J. Appl. Phys. 86, 1 (1999). http://dx.doi.org/10 . 1063/1.371145

[82] S. Nakamura, Science 281, 956 (1998). http://dx. doi.org/10.1126/science.281.5379.956

[83] M. Hansen, P. Fini, L. Zhao, A. C. Abare, L. A. Coldren, J. S. Speck and S. P. DenBaars, Appl. Phys. Lett. 76, 529 (2000). http://dx.doi.org/10.1063/1. 125808

[84] J. D. Heber, C. Gmachl, H. M.Ng and A. Y. Cho, Appl. Phys. Lett. 81, 1237 (2002). http://dx.doi.org/10. 1063/1. 1500412

[85] R. Singh, D. Doppalapudi T. D. Moustakas and L. T. Romano, Appl. Phys. Lett. 70, 1089 (1997). http:// dx.doi.org/10.1063/1.118493

[86] K. Dovidenko, S. Oktyabrsky, J. Narayan and M. Razeghi, J. Appl. Phys. 79, 2439 (1996). http://dx. doi.org/10.1063/1.361172

[87] F. A. Ponce and D. P. Bour, Nature 386, 351 (1997). http://dx.doi.org/10.1038/386351a0

[88] F. Bernardini, V. Fiorentini and D. Vanderbilt, Phys. Rev. B 56, R10024 (1997). http://dx.doi.org/10. 1103/PhysRevB.56.R10024

[89] Q. Wang, T. Wang,J. Bai, A. G. Cullis, P. J. Parbrook and F. Ranalli, J. Appl. Phys. 103, 123522 (2008). http://dx.doi.org/10.1063/1.2939568 